\title{
Differences between rates of responding emitted during simple and multiple schedules
}

\author{
FRANCES K. McSWEENEY \\ Washington State University, Pullman, Washington 99164
}

\begin{abstract}
Pigeons pecked keys for food reinforcers delivered by several variable-interval and multiple variable-interval schedules. The rates of responding emitted during the simple schedules were not systematically different from the rates emitted during the multiple schedules when the components of the multiple schedule were identical. The rates of responding emitted during the components were usually greater than the rates emitted during comparable simple schedules when the components were more favorable than the added components of the multiple schedules. Response rates during the components were not significantly lower than those during comparable simple schedules when the components were less favorable. The observation of higher rates of responding during the more favorable components conforms to a prediction of several additive theories (e.g., Rachlin, 1973) but violates a prediction of Herrnstein's (1970) theory. However, the additive theories are brought into question by the fact that changing the location of the discriminative stimuli did not change the pattern of results.
\end{abstract}

Two major theories make different predictions about the relation between the rates of responding emitted during simple and multiple schedules. A theory proposed by Herrnstein (1970) predicts that rate of responding during a simple schedule will be greater than or equal to the rate emitted when the same schedule appears as one component of a multiple schedule. On the other hand, several additive theories (e.g., Gamzu \& Schwartz, 1973; Hearst \& Jenkins, 1974; Rachlin, 1973) predict that the relation between the two rates of responding may depend on the relation between the rates of reinforcement supplied by the components of the multiple schedule.

Herrnstein (1970) proposed that Equation 1 describes the behavior of animals responding on simple, concurrent, and multiple schedules of reinforcement.

$$
P_{1}=\frac{k R_{1}}{R_{1}+m R_{2}+R_{0}} .
$$

$P_{1}$ is the rate of responding emitted for a rate of reinforcement equal to $R_{1} . R_{2}$ is the rate of reinforcement obtained by making a second response, $P_{2}$, if one is available. The symbols $\mathrm{k}, \mathrm{m}$, and $\mathrm{R}_{0}$ are parameters that are estimated from the data with certain restrictions (Herrnstein, 1974).

Reprints may be obtained from the author, Department of Psychology, Washington State University, Pullman, Washington 99164. The author wishes to thank W. D. Norman for his help with an earlier version of this paper. The results of Experiment 1 were presented at the 1977 meeting of the Western Psychological Association. The results of Experiment 2 were presented at the 1979 meeting of the Association for Behavior Anatysis.
Equation 1 predicts that the rate of responding emitted during a simple schedule should be greater than or equal to the rate of responding emitted during a comparable component of a multiple schedule. $\mathbf{R}_{2}$ is $\mathbf{0}$ when subjects respond on simple schedules, but it is greater than 0 when subjects respond on multiple schedules, unless the added component is extinction. The $k$ and $R_{0}$ parameters should remain constant from the schedule to the component if other variables, such as the animal's state of deprivation and the form of the response required for reinforcement, remain constant (Herrnstein, 1974; Herrnstein \& Loveland, 1974). Therefore, the addition of $R_{2}$ should create a lower rate of responding during a component than during a comparable simple schedule, unless $m$ equals 0 . If $\mathrm{m}$ equals 0 , or if the added component is extinction, then the two rates of responding should be equal. But, multiple schedule responding should not be greater than comparable simple schedule responding.

Several additive theories make a different prediction about the relation between simple and multiple schedule responding. They distinguish between two different types of responses. Instrumental responses occur whenever a response is required for reinforcement. Additive responses occur whenever different stimuli signal different rates of reinforcement. These two types of responses may interact to determine the final rate of responding if the form of the instrumental response has been properly chosen.

According to the additive theories, rates of responding during simple schedules should equal the rates emitted during multiple schedules that provide identical simple schedules in the components [e.g., multiple variable-interval $\mathrm{x}$ variable-interval $\mathrm{x}$ (mult 
VI x VI x) schedules]. Subjects responding on these simple and component schedules should emit instrumental responses because both require a response for reinforcement. But no additive responses should occur because no stimuli differentially predict reinforcement. Because all of the responses are instrumental responses, the rates of responding emitted during the schedules should equal the rates emitted during the components if factors that control instrumental responses, such as the rate of reinforcement (Rachlin, 1973), are equal between them.

The predictions are more complicated when the components of the multiple schedule provide different rates of reinforcement (e.g., mult VI x VI y schedules). Then the theories predict that rate of responding during the VI $\mathrm{x}$ component of a multiple schedule will be greater than the rate emitted during a VI $x$ schedule when the VI $x$ component provides a higher rate of reinforcement than the VI y component. The additive theories differ slightly in detail, but all would agree that additive responses should add to properly chosen instrumental responses during the more favorable component of a multiple schedule. If the rates of instrumental responding emitted during that component are equal to those emitted during the simple schedule, as they would be if the schedule and component provided the same rate of reinforcement, then the addition of additive to instrumental responses should create a higher rate of responding during the component than during the schedule.

Finally, Hearst and Jenkins (1974) and Rachlin (1973) predict that rate of responding during the VI x component of a mult VI x VI y schedule should be less than the rate emitted during a VI $x$ schedule, when the VI $x$ component of the multiple schedule provides a lower rate of reinforcement than the VI y component. Hearst and Jenkins and Rachlin argue that additive responses may subtract from properly chosen instrumental responses during the less favorable component of a multiple schedule. If the rates of instrumental responding emitted during the component and simple schedule were equal, then the subtraction of additive from instumental responses for the component, but not for the schedule, would produce a lower rate of responding during the component than during the schedule.

The present experiments tested these predictions. Experiment 1 compared rates of responding during several VI $x$ and mult VI $x$ VI $x$ schedules. Experiment 2 compared rates of responding during several VI $x$ and mult VI $x$ VI y schedules. Experiment 3 was similar to Experiment 2 except that the stimuli that signaled the components of the multiple schedules did not appear on the instrumental response key. The keypeck served as the instrumental response in all experiments because both types of theories make clear predictions for this response.

\section{EXPERIMENT 1}

The additive theories predict that rates of responding during VI $x$ schedules should equal the rates emitted during the components of mult VI x VI x schedules. Herrnstein (1970) predicts that responding during the components should be less than or equal to responding during the schedule. Several studies found a lower rate during multiple schedules than during comparable simple schedules (Bloomfield, 1967; Carr \& Reynolds, cited in Staddon, 1974; de Villiers, 1972; \& Terrace, cited in Herrnstein, 1970), but their results are inconclusive. Two of the studies are unpublished; the other two were not designed to test this prediction, and procedural flaws make their results difficult to interpret. Bloomfield (1967) presented the components of the multiple schedules on successive days. Therefore, his results may not apply to more typical multiple schedules which present both components in a single session. De Villiers (1972) presented each schedule only once. Therefore, fluctuations in the rates of responding that occurred over time may have confounded his results. The rates of responding emitted during the simple schedules should have been replicated after the multiple schedules to avoid this problem.

Two studies found no differences between the rates of responding (McSweeney \& Dericco, 1976; Spealman $\&$ Gollub, 1974), but these studies are incomplete. Neither study examined the prediction over a wide range of rates of reinforcement.

The present experiment varied rates of reinforcement over a wide range to test the generality of the results. This experiment, and the ones that follow, presented baseline simple schedules before and after each mult VI x VI x or mult VI x VI y schedule to distinguish changes in the rates of responding generated by the schedules from fluctuations in the rates of responding over time.

\section{Method}

Subjects. Four male homing pigeons, maintained at $80 \%$ to $85 \%$ of their free-feeding body weights, served as subjects. The subjects had previously served as subjects in the McSweeney and Dericco (1976) study.

Apparatus and Procedure. The apparatus was the one used in the McSweeney and Dericco (1976) study. It was a standard threekey, aluminum, Grason-Stadler pigeon station, Model E6446C, enclosed in a Grason-Stadler, Model E3125A-300, aluminum, sound-attenuating chamber. The houselight continuously illuminated the chamber during the sessions and white noise was continuously present. Electromechanical equipment located in another room scheduled the experimental events.

The subjects had been trained to peck the response keys in an earlier study (McSweeney \& Dericco, 1976). Therefore, they were placed directly on the following series of VI $x$ and mult VI $x$ VI $x$ schedules, presented in the following order: VI 15-sec (40), mult VI 15-sec VI 15-sec (40), VI 15-sec (40), VI 4-min (15), mult VI 4-min VI 4-min (15), VI 4-min (15), VI 12-min (5), mult VI 12-min VI 12-min (5), VI 12-min (5), VI 16-min (3), mult VI 16-min VI 16min (3), VI 16-min (3), VI 30-sec (40), mult VI 30-sec VI 30-sec (40), and VI $30-\sec (40)$. The number in parentheses following each sched- 
ule indicates the number of reinforcers that were presented per session for that schedule. The number varied from schedule to schedule to prevent the sessions from becoming extremely long. Sessions were conducted daily, six to seven times per week.

A green light illuminated the center response key, located directly above the food magazine, during the VI schedules. Green and white lights alternated every $90 \mathrm{sec}$ on the center response key during the multiple schedules. Pecks on the center key produced reinforcement and a brief feedback click. Pecks on the other keys were ineffective: they did not produce feedback clicks or reinforcers and they were not recorded. These keys were not illuminated.

Reinforcers consisted of $5 \mathrm{sec}$ access to a magazine containing mixed grain. They were scheduled according to a 20 -interval series constructed by a procedure outlined by Catania and Reynolds (1968, Appendix 2). Responses were not recorded and the key light was extinguished during each presentation of the magazine, but the component timer did not stop. The stimulus appropriate to the nex somponent appeared at the end of the food presentation if the previous component had ended during the presentation.

All reinforcers were programmed by a single VI series regardless of whether the subjects responded on a VI or multiple schedule. Reinforcers that became available but were not collected during one component of the multiple schedule were collected by the next response regardless of the color of the key when the response occurred. Reinforcers were not canceled when the color of the key light changed and they were not held over for the next appearance of the color in which they had become available.

Subjects responded on each schedule until responding stabilized. Responding was stable when rates of responding during the last five sessions for which that schedule was presented all fell within the range of the rates of responding emitted on the same schedule during the earlier sessions. That is, a range of rates of responding was calculated for each simple schedule, and for each component of each multiple schedule, by looking at the rates of responding emitted by a particular subject during all but the last five sessions for which that schedule was presented. Responding was considered to be stable for that subject, responding on that schedule, if rates of responding during the last five sessions fell within this range. Responding was considered to be stable for a multiple schedule only when rates of responding during both components were stable. An average of 24.6 sessions were conducted for each schedule.

\section{Results}

Table 1 presents mean rates of responding emitted during each VI schedule and during each component of each multiple schedule, calculated over the last five sessions for which each schedule was available. Rates of responding emitted during the VI schedules were calculated by dividing the number of responses emitted per session by the total session time. Rates of responding emitted during the components of the multiple schedules were calculated by dividing the number of responses emitted during each component by the time during which that component was available. Magazine presentation time was excluded from all calculations.

Matched $t$ tests compared rates of responding emitted during the green components of the multiple schedules with rates of responding emitted during the preceding simple schedule. The value of the test for each multiple schedule and its level of significance appear in the row for the multiple schedule in Table 1.

Table 1 shows that rates of responding during the VI x schedules were not systematically different from the rates emitted during the components of the mult VI x VI x schedules. The only comparison between the simple and multiple schedule responding that reached statistical significance was that between the mult VI 15 -sec VI 15 -sec and the preceding VI 15-sec schedule. But this difference may have been produced by fluctuations in responding over time, rather than by differences between the schedules. The mean rate of responding during the mult VI 15-sec VI 15-sec schedule did not differ in the same direction from the mean rates of responding during its two surrounding VI schedules. Rather, response rates increased from the first VI 15-sec schedule to the multiple schedule and then increased again from the multiple schedule to the second VI 15-sec schedule.

Table 1

Mean Rates of Responding Emitted During Each VI Schedule and During Each Multiple Schedule Over the Last Five Sessions for Which That Schedule Was Available

\begin{tabular}{|c|c|c|c|c|c|c|c|c|c|c|c|}
\hline \multirow[b]{2}{*}{ Schedule } & \multicolumn{2}{|c|}{ Subject 2455} & \multicolumn{2}{|c|}{ Subject 2560} & \multicolumn{2}{|c|}{ Subject 2457} & \multicolumn{2}{|c|}{ Subject 2454} & \multicolumn{2}{|c|}{ Mean } & \\
\hline & Green & White & Green & White & Green & White & Green & White & Green & White & \\
\hline $\begin{array}{l}\text { VI 15-sec } \\
\text { mult VI } 15-\sec \text { VI } 15-\mathrm{sec} \\
\text { VI 15-sec }\end{array}$ & $\begin{array}{l}42.7 \\
50.7 \\
51.7\end{array}$ & 55.3 & $\begin{array}{l}46.5 \\
48.0 \\
72.5\end{array}$ & 58.1 & $\begin{array}{l}42.4 \\
51.1 \\
46.7\end{array}$ & 37.6 & $\begin{array}{l}37.6 \\
44.6 \\
53.5\end{array}$ & 43.4 & $\begin{array}{l}42.3 \\
48.6 \\
56.1\end{array}$ & 48.6 & $\mathrm{t}(3)=3.85, \mathrm{p}<.05$ \\
\hline $\begin{array}{l}\text { VI 4-min } \\
\text { mult VI 4-min VI 4-min } \\
\text { VI 4-min }\end{array}$ & $\begin{array}{l}27.6 \\
27.7 \\
28.6\end{array}$ & 26.7 & $\begin{array}{l}58.3 \\
75.2 \\
74.3\end{array}$ & 79.1 & $\begin{array}{r}6.2 \\
40.8 \\
28.9\end{array}$ & 31.2 & $\begin{array}{l}41.0 \\
41.8 \\
42.5\end{array}$ & 40.7 & $\begin{array}{l}33.3 \\
46.4 \\
43.6\end{array}$ & 44.4 & $t(3)=1.61, p>.10$ \\
\hline $\begin{array}{l}\text { VI 12-min } \\
\text { mult VI 12-min VI 12-min } \\
\text { VI 12-min }\end{array}$ & $\begin{array}{l}11.8 \\
13.4 \\
15.7\end{array}$ & 14.4 & $\begin{array}{l}71.5 \\
47.0 \\
74.3\end{array}$ & 41.9 & $\begin{array}{l}6.3 \\
5.7 \\
9.8\end{array}$ & 3.2 & $\begin{array}{l}42.4 \\
42.0 \\
34.0\end{array}$ & 38.5 & $\begin{array}{l}33.0 \\
27.0 \\
33.5\end{array}$ & 24.5 & $t(3)=.96, p>.10$ \\
\hline $\begin{array}{l}\text { VI 16-min } \\
\text { mult VI 16-min VI 16-min } \\
\text { VI 16-min }\end{array}$ & $\begin{array}{l}14.6 \\
14.6 \\
12.5\end{array}$ & 16.8 & $\begin{array}{l}70.0 \\
61.3 \\
65.4\end{array}$ & 48.5 & $\begin{array}{r}13.8 \\
1.1 \\
5.5\end{array}$ & .9 & $\begin{array}{l}39.8 \\
41.6 \\
48.5\end{array}$ & 43.2 & $\begin{array}{l}34.6 \\
29.7 \\
33.0\end{array}$ & 27.4 & $\mathrm{t}(3)=1.41, \mathrm{p}>.10$ \\
\hline $\begin{array}{l}\text { VI 30-sec } \\
\text { mult VI } 30-\text { sec VI } 30-\mathrm{sec} \\
\text { VI } 30-\mathrm{sec}\end{array}$ & $\begin{array}{l}39.4 \\
56.6 \\
39.7\end{array}$ & 47.4 & $\begin{array}{l}98.2 \\
91.4 \\
86.5\end{array}$ & 87.7 & $\begin{array}{l}78.1 \\
80.3 \\
70.6\end{array}$ & 69.2 & $\begin{array}{l}56.8 \\
64.8 \\
49.5\end{array}$ & 61.4 & $\begin{array}{l}68.1 \\
73.3 \\
61.6\end{array}$ & 66.4 & $t(3)=1.02, p>.10$ \\
\hline
\end{tabular}




\section{EXPERIMENT 2}

Experiment 2 examined the relation between rates of responding during VI $\mathrm{x}$ and mult VI $\mathrm{x}$ VI y schedules. As argued earlier, Herrnstein (1970) predicts that rates of responding during the VI $\mathrm{x}$ components should be less than or equal to those emitted during the VI $x$ schedules. The additive theories predict that responding during the components should be greater than during the schedules when the VI x components supply higher rates of reinforcement than the VI y components. Hearst and Jenkins (1974) and Rachlin (1973) predict that rates of responding during the components should be less than those emitted during the schedules when the VI x components supply lower rates of reinforcement than the VI $y$ components.

No studies have examined the relation between the rates of responding during the less favorable components of multiple schedules and comparable simple schedules. But several studies have compared simple schedules with more favorable components (Freeman, 1971; Halliday \& Boakes, 1974; Hearst \& Gormley, 1976; Jaffe, 1973; Pear \& Wilkie, 1971). None of these studies provide conclusive results, however. Three studies may not have tested the additive theories because they used rats as subjects (Freeman, 1971; Jaffe, 1973; Pear \& Wilkie, 1971). The predictions of the additive theories do not always apply to responses emitted by rats (e.g., Rachlin, 1973). The studies by Halliday and Boakes (1974) and by Hearst and Gormley (1976) supported the predictions of the additive theories using pigeons as subjects. But they studied only one multiple schedule (mult VI ext), and Hearst and Gormley did not recover baseline rates of responding during the simple schedules after the presentation of the multiple schedule. Therefore, their results cannot be distinguished from fluctuations in responding over time.

The present study examined the differences between simple and multiple schedule responding for several schedules of reinforcement. It investigated the differences for both the more and less favorable components of the multiple schedule.

\footnotetext{
Method

Subjects. The subjects were the same as those used in Experiment 1 . Again, they were maintained at $80 \%$ to $85 \%$ of their freefeeding body weights.

Apparatus and Procedure. The apparatus was the same as that used for Experiment 1. The procedure differed from that used in Experiment 1 in only two ways. First, two independent variableinterval schedules presented the reinforcers during the components of the multiple schedules. Each VI schedule advanced only when that component was available to the subject. Reinforcers that became available but were not collected during one component were canceled when the component changed. They were not held over for the next appearance of that component schedule. Second, different schedules were conducted. The following schedules were presented in the following order: VI 1 -min $(40)$, mult VI 1 -min
}

VI 4-min (20), VI 1-min (40), mult VI 1-min VI 15-sec (4;), VI 1-min (40), mult VI 1-min VI $2-$ min (30), VI 1-min (40), mult VI 1-min VI 10-min (20), and VI 1 -min (40). The number in parentheses represents the number of reinforcers that were presented per session for that schedule. The stability criterion used in Experiment 1 was used here, and an average of 27.6 sessions were conducted per schedule. The green light signaled the VI 1-min component of each schedule.

\section{Results}

Table 2 presents the mean rates of responding emitted during each VI schedule and during each component of each multiple schedule. Rates of responding were calculated as they were for Table 1 . Matched $t$ tests compared rates of responding emitted during the VI 1-min component of each multiple schedule with the rates emitted during the preceding VI 1-min schedule. The values of the tests and their levels of significance appear in the rows for multiple schedules in Table 2 .

The results presented in Table 2 display some variability both across and within subjects. But the data suggest that the rate of responding during the VI 1-min component was greater than that emitted during the VI 1-min schedule when the added component of the multiple schedule provided a much lower rate of reinforcement than the VI 1-min component. The rate of responding during the VI 1-min component was greater than that emitted during the surrounding simple schedules in eight of eight comparisons for the mult VI 1-min VI 10-min schedule, in six of eight comparisons for the mult VI 1-min VI 4-min schedule, and in five of eight comparisons for the mult VI 1-min VI 2-min schedule. The difference between simple and multiple schedule responding was statistically significant for the mult VI 1-min VI 10-min schedule ( $p<$ $.05)$, marginally significant for the mult VI 1-min VI 4 min schedule $(.05<\mathrm{p}<.10)$, and nonsignificant for the mult VI 1 -min VI 2 -min schedule $(p>.10)$. In all cases, the mean rate of responding during the multiple schedules differed in the same direction from the mean rates emitted during its surrounding simple schedules, indicating that the differences between simple and multiple schedule responding were produced by changes in the schedule rather than by fluctuations in responding over time.

The data in Table 2 generally show that the rate of responding during the VI 1-min component was less than that emitted during the VI 1-min schedule when the added component of the multiple schedule supplied a higher rate of reinforcement than the VI 1-min component. Responding during the component was less than that during the surrounding simple schedules in six of eight comparisons. But this difference was not statistically significant $(p>.10)$. Therefore, more data are needed before any conclusions may be drawn. 
Table 2

Mean Rates of Responding Emitted During Each VI Schedule and During Each Component of Each Multiple Schedule During the Last Five Sessions for Which That Schedule Was Available

\begin{tabular}{|c|c|c|c|c|c|c|c|c|c|c|c|}
\hline & \multicolumn{2}{|c|}{ Subject 2455} & \multicolumn{2}{|c|}{ Subject 2560} & \multicolumn{2}{|c|}{ Subject 2457} & \multicolumn{2}{|c|}{ Subject 2454} & \multicolumn{2}{|c|}{ Mean } & \\
\hline & VI 1-min & $\mathrm{O}$ & $\mathrm{VI} 1-\mathrm{min}$ & $\mathrm{O}$ & VI $1-\min$ & 0 & VI 1-min & o & VI $1-\mathrm{min}$ & 0 & \\
\hline VI $1-\mathrm{min}$ & 50.4 & & 79.9 & & 74.5 & & 43.5 & & 62.1 & & \\
\hline$-\min$ VI 4-min & 65.6 & 27.4 & 110.6 & 82.6 & 63.5 & 14.6 & 74.0 & 42.2 & 78.4 & 41.7 & $t(3)=1.67, .05<p<.10$ \\
\hline VI $1 \cdot \min$ & 45.5 & & 82.9 & & 76.3 & & 48.2 & & 63.2 & & \\
\hline mult VI $1-\min$ VI $15-\mathrm{sec}$ & 35.7 & 146.7 & 89.9 & 137.1 & 65.1 & 159.6 & 44.3 & 142.3 & 58.8 & 146.4 & $t(3)=1.08, p>.10$ \\
\hline VI $1-\min$ & 45.4 & & 84.5 & & 76.6 & & 45.4 & & 63.0 & & \\
\hline mult VI $1-\mathrm{min}$ VI 2-min & 41.1 & 32.3 & 93.1 & 82.5 & 67.7 & 60.0 & 52.1 & 42.1 & 63.5 & 54.2 & $t(3)=.14, p>.10$ \\
\hline VI $1-\min$ & 40.6 & & 84.7 & & 69.6 & & 45.5 & & 60.1 & & \\
\hline mult VI $1-\min$ VI 10-min & 58.7 & 26.5 & 97.3 & 68.0 & 72.8 & 38.1 & 59.0 & 36.8 & 72.0 & 42.4 & $t(3)=3.79, p<.05$ \\
\hline VI 1-min & 46.2 & & 86.2 & & 64.1 & & 45.7 & & 60.6 & & \\
\hline
\end{tabular}

Note $-O=$ other

\section{EXPERIMENT 3}

The results of Experiment 2 generally supported the additive theories' prediction of higher response rates during the more favorable components of multiple schedules than during comparable simple schedules. As argued earlier, the additive theories attribute these higher response rates to the interaction of additive and instrumental responses. Therefore, the theories also predict that higher response rates should not be found if the two types of responses do not interact.

One way to prevent their interaction would be to move the additive responses away from the instrumental response key. This could be done by moving the stimuli that signal the components away from the instrumental key. All of the additive theories argue that additive responses will be directed toward the stimulus signaling reinforcers. Therefore, moving the discriminative stimulus should separate instrumental from additive responses. The present experiment tested this prediction.

\footnotetext{
Method

Subjects. The subjects were the same as those used in Experiments 1 and 2 , maintained at $80 \%$ to $85 \%$ of their free-feeding weights.

Apparatus and Procedure. The apparatus was the same as that used in Experiments 1 and 2. The procedure differed from that used in Experiment 2 in only two ways. First, the stimuli that signaled the components of the multiple schedule appeared on the left and right keys, but pecking the center key produced reinforcers. The center, instrumental key was constantly illuminated with green light. A white light appeared on the key to the subject's left, as it faced the wall containing the food magazine, whenever the VI 1-min component or schedule was available. A red light appeared on the right key during the other component of the multiple schedule. Pecks on the signal keys were not recorded because of a shortage of equipment. Second, different schedules were conducted. The following schedules were presented in the following order: VI $1-$ min (40), mult VI $1-$ min VI 4-min (25), VI $1-\min (40)$, mult VI $1-\min$ VI $15-\sec (40)$, VI I-min (40), mult VI $1-\min$ VI $10-\min (25)$, VI $1-\min (40)$, mult VI $1-\min$ VI $30-\sec (40)$, and VI $1-\min (40)$. The number in parentheses represents the number of reinforcers
}

that were presented per session for that schedule. The stability criterion used in Experiments 1 and 2 was used here, and an average of 43.9 sessions were conducted for each schedule.

\section{Results}

Table 3 presents mean rates of responding emitted during each VI schedule and during each component of each multiple schedule. Rates of responding were calculated as they were for Tables 1 and 2. Again, matched $t$ tests compared rates of responding during the VI 1-min component of each multiple schedule with the rates emitted during the preceding simple schedule. The values of the tests and their levels of significance appear in the rows for multiple schedules in Table 3.

Again, there is some variability in the results presented in Table 3, but the pattern of results was similar to that obtained in Experiment 2. Rates of responding during the VI 1-min components were greater than those emitted during the VI 1-min schedules when the VI 1-min component was more favorable. Rates of responding during the VI 1-min components exceeded the rates emitted during their surrounding simple schedules in seven of eight comparisons for the mult VI 1-min VI 10-min schedule and in six of eight comparisons for the mult VI 1-min VI 4-min schedule. These differences between simple and multiple schedule responding were statistically significant for both schedules $(p<.05)$. Mean rate of responding during the multiple schedule differed from the mean rates emitted during its two surrounding simple schedules in the same direction, indicating that the differences were produced by changes in the schedule rather than by fluctuations in responding over time.

Again, the results were less consistent when the VI 1-min component was less favorable. Subjects frequently emitted lower rates of responding during the components than during the comparable simple schedules. But neither the difference between simple and mult VI 1-min VI 30-sec responding nor the difference between simple and mult VI 1-min VI $15-\mathrm{sec}$ 
Table 3

Mean Rates of Responding Emitted During Each VI Schedule and During Each Component of Each Multiple Schedule During the Last Five Sessions for Which That Schedule Was Available

\begin{tabular}{|c|c|c|c|c|c|c|c|c|c|c|c|}
\hline \multirow[b]{2}{*}{ Schedule } & \multicolumn{2}{|c|}{ Subject 2455} & \multicolumn{2}{|c|}{ Subject 2560} & \multicolumn{2}{|c|}{ Subject 2457} & \multicolumn{2}{|c|}{ Subject 2454} & \multicolumn{2}{|c|}{ Mean } & \\
\hline & VI 1-min & 0 & VI 1-min & $\mathrm{O}$ & VI 1-min & 0 & VI $1-\min$ & $\mathrm{O}$ & VI 1-min & $\mathrm{O}$ & \\
\hline VI 1-min & 39.9 & & 73.8 & & 37.8 & & 49.5 & & 50.3 & & \\
\hline mult VI $1-\min$ VI $4 \mathrm{~min}$ & 51.8 & 33.1 & 85.3 & 65.9 & 36.6 & 14.2 & 56.8 & 46.1 & 57.6 & 39.8 & $\mathrm{t}(3)=2.42, \mathrm{p}<.05$ \\
\hline VI $1-\min$ & 40.9 & & 76.3 & & 39.9 & & 55.4 & & 53.1 & & \\
\hline mult VI 1-min VI 15-sec & 50.9 & 89.4 & 44.9 & 81.8 & 33.4 & 40.7 & 42.5 & 61.3 & 42.9 & 68.3 & $t(3)=1.19, p>.10$ \\
\hline VI 1-min & 52.7 & & 70.9 & & 34.0 & & 58.8 & & 54.1 & & \\
\hline mult VI 1-min VI 10-min & 63.4 & 21.2 & 96.1 & 50.0 & 66.9 & 32.0 & 63.0 & 40.6 & 72.4 & 36.0 & $t(3)=2.78, p<.05$ \\
\hline VI $1-\min$ & 60.2 & & 95.2 & & 26.4 & & 67.1 & & 62.2 & & \\
\hline mult VI $1-\min$ VI $30-\mathrm{sec}$ & 48.7 & 84.1 & 67.9 & 110.5 & 35.0 & 45.8 & 70.4 & 76.0 & 55.5 & 79.1 & $t(3)=.83, p>.10$ \\
\hline VI $1-\mathrm{min}$ & 39.6 & & 92.9 & & 29.7 & & 74.7 & & 59.2 & & \\
\hline
\end{tabular}

Note-O= other.

responding reached statistical significance $(p>.10)$.

Figure 1 summarizes the results of all three experiments. It presents the differences between rates of responding during simple and multiple schedules (in responses per minute) plotted as a function of the rate of reinforcement supplied by the added component of the multiple schedule (in reinforcers per hour). The points represent the results for the mean of all subjects responding in each experiment. Each set of axes represents the results of one experiment. The horizontal lines at 0 responses/min represent equality between rates of responding during the VI $\mathrm{x}$ schedules and the VI $x$ components of the intervening multiple schedule. The vertical lines at 60 reinforcers/h drawn on the axes for Experiments 2 and 3 represent the point at which the two components of the muitiple schedule were identical (mult VI x VI x). Points to the left of this line represent schedules in which the added (VI y) component of the multiple schedule provided a lower rate of reinforcement than the 60 reinforcers/h provided by the VI 1 -min (VI x) component. Points to the right of this line represent conditions in which the VI y component of the multiple schedule provided a higher rate of reinforcement than the VI $x$.

The points plotted in the figure were calculated as follows. Rate of responding during each VI x schedule was calculated by averaging the five-session means for the two successive presentations of that schedule. This average was subtracted from the five-session mean of the rates of responding emitted during the comparable VI x component of the multiple schedule that intervened between the two simple schedules. The points for 60 reinforcers/h were taken from McSweeney and Dericco (1976), which used the same subjects and procedure. The subjects in the McSweeney and Dericco study responded on the following schedules presented in the following order: VI 1-min, mult VI 1-min VI 1-min, VI 1-min, mult VI 1-min VI 1-min, and VI 1-min. The points plotted in the figure were obtained by averaging rates of responding during the

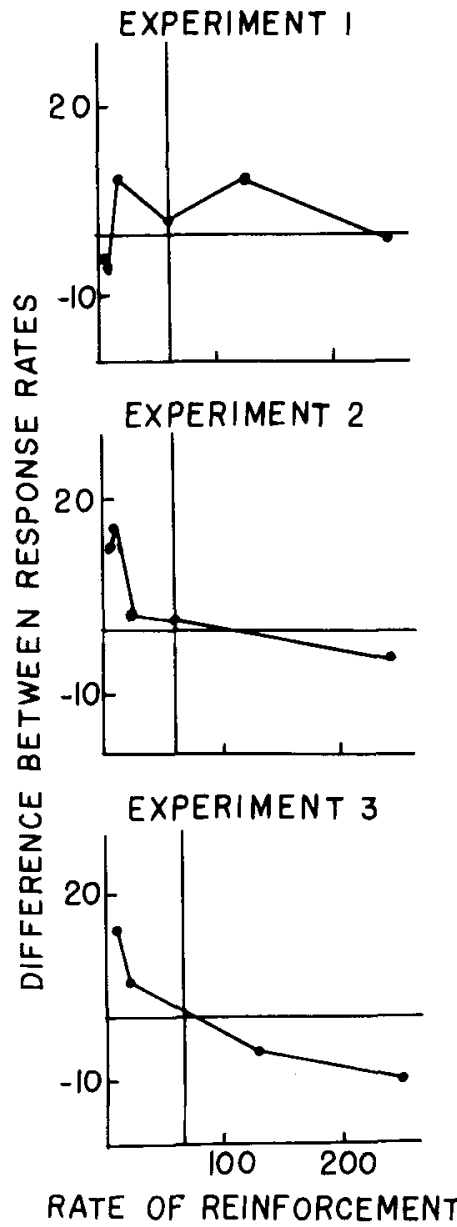

Figure 1. Differences between rates of responding during simple and multiple schedules plotted as a function of the rate of reinforcement supplied by the added component of the multiple schedule, for the mean of all subjects responding in each experiment. Differences are reported in responses per minute and rates of reinforcement are reported in reinforcers per hour. Each set of axes represents an experiment. The horizontal line at 0 responses/min represents equality between simple and multiple schedule responding. The vertical lines for Experiments 2 and 3 represent the points at which the two components of the multiple schedule were idenical. 
VI 1-min schedules that preceded and followed each multiple schedule for the mean of all subjects. Each of these averages was subtracted from the mean rate of responding during the comparable component of the intervening multiple schedule. The two numbers that resulted were averaged to produce the points plotted in the figure.

A repeated measure analysis of variance applied to the points plotted in Figure 1 for each experiment revealed that the points plotted for Experiment 1 are not significantly different from each other $[F(5,15)=$ $1.85, \mathrm{p}>$.10]. Those plotted for Experiment 2 differ significantly $[\mathrm{F}(4,12)=5.48, \mathrm{p}<.01]$. Those plotted for Experiment 3 are marginally significant $[F(3,9)=$ $3.25, .05<\mathrm{p}<.10$ ]. Comparisons of individual pairs of points for Experiment 2 by matched t tests showed that two of the three points plotted farthest to the left of the vertical line did not differ significantly from each other $[t(12)=1.16, p>.10]$, but did differ significantly from each of the other three points $(p<.01)$. In turn, the other three points were not significantly different from each other $(p \geqslant .10)$. Comparing individual points for Experiment 3 revealed a similar pattern. The two points to the left of the vertical line did not differ significantly from each other $[\mathrm{t}(9)=1.33, \mathrm{p}>.10]$, but did differ significantly from both points to the right of the line $(p<.05)$. The two points to the right of the line did not differ significantly from each other $[t(9)=.88, p>.10]$.

\section{DISCUSSION}

The finding that the rates of responding emitted during the VI $x$ and mult VI $x$ VI $x$ schedules were not systematically different is consistent with the additive theories. It is also consistent with Herrnstein's theory if the $\mathrm{m}$ parameter is assumed to be 0 .

The higher rates of responding emitted during the more favorable VI 1-min components than during the comparable simple schedules in Experiments 2 and 3 contradict Herrnstein's (1970) theory, which predicts lower or equal response rates. One way to reconcile these results with the theory is to assume that the size of $k$ or $\mathbf{R}_{\mathbf{0}}$ or both changed from the simple to the component schedules. Making this assumption has two disadvantages, however. First, the assumption would be incompatible with earlier statements about the factors that control the size of $k$ and $R_{0}$ (e.g., Herrnstein, 1974; Herrnstein \& Loveland, 1974). Second, assumptions about the changes in the size of $\mathrm{k}$ and $\mathrm{R}_{\mathbf{0}}$ must be qualified by noting that the changes occurred only when the VI $x$ component supplied a higher rate of reinforcement than the VI y component. That assumption appears gratuitous and cumbersome at the present time.

A second way to reconcile the higher rates of responding with Herrnstein's theory is to assume that the theory applies to, or could be modified to apply to, instrumental responses only. The theory would not apply to multiple schedules when additive responses interact with instrumental responses. In that case, Herrnstein's theory would be tested only during multiple schedules which used instrumental responses that do not add to additive responses, such as the treadle press (Hemmes, 1973; McSweeney, 1978; Westbrook, 1973). Testing Herrnstein's theory for multiple schedules that use keypecks as the instrumental responses would require adequate ways of separating additive from instrumental responses. These techniques are not available at the present time.

The higher rates of responding emitted during the more favorable components of the multiple schedules in Experiment 2 are consistent with all three additive theories. But the results of Experiment 3 may contradict the additive theories' explanation of these results. If the interaction of instrumental and additive responses had created the higher response rates, as the additive theories argue, then higher response rates should not have occurred in Experiment 3, which was designed to prevent this interaction. But they did.

If the results of Experiment 3 do contradict the additive theories, then they may join the results of several other experiments that also question the additive theories' explanation of responding during multiple schedules in which the discriminative stimuli do not appear on the instrumental response key. The additive theories have argued that positive behavioral contrast, like the present difference between simple and multiple schedules, occurs only when additive responses add to instrumental responses. Therefore, behavioral contrast should also occur only when the discriminative stimuli appear on the instrumental key. Several studies have supported this prediction by showing that contrast does not occur when diffuse stimuli signal the components (Bottjer, Scobie, \& Wallace, 1977; Redford \& Perkins, 1974; Schwartz, 1974,1975 ) or when the discriminative stimuli are moved to another key (Keller, 1974; Schwartz, 1975; Schwartz, Hamilton, \& Silberberg, 1975; White \& Braunstein, 1979). But a growing number of studies have contradicted the additive theories by reporting contrast when the stimuli are diffuse (Hearst \& Gormley, 1976; Westbrook, 1973) or when the stimuli appear on a second key (Schwartz, 1978; Woodruff, 1979).

It is not known whether Experiment 3 represents a study using the diffuse stimulus, time, or one using stimuli on a signal key, because responses to the signal key were not recorded. The experiment would be similar to studies using diffuse stimuli if the subjects ignored the stimulus key and therefore did not respond on it. It would be similar to signal-key multiple schedules if subjects attended to and responded on that key. Regardless of which type of study it is, the results of Experiment 3 are presently similar to those of studies that contradict the additive theories 
when the discriminative stimuli do not appear on the instrumental response key.

The results of Experiment 3 might be reconciled with the additive theories by future experiments, however. Each of the additive theories can provide an explanation for these results. For example, Rachlin (1973) states that additive responses may be directed by variables other than the location of the stimuli that predict reinforcers. Therefore, additive responses might be directed to the response key, producing the results of Experiment 3, even if the stimuli did not appear there.

Schwartz (1973) has provided a more detailed explanation for these results. He has argued that additive responses elicited by a diffuse tone could be directed to a response key if the subjects were given special training. During special training, the combination of the diffuse tone and a green light appearing on the response key signaled the availability of free food. The absence of the tone plus the presence of a red light signaled the absence of food. Then, Schwartz removed the visual stimuli and showed that the subjects continued to direct their additive pecks to the response key whenever the diffuse tone was presented.

A similar argument could be offered for the present results. The subjects in Experiment 3 had responded on multiple schedules during which the components alternated in time for a long period before the experiment began. If it is assumed that time is a diffuse stimulus like the tone, then these subjects had had special training in which the combination of certain diffuse time stimuli and certain visual stimuli differentially signaled food. If it is also assumed that the subjects ignored the visual stimuli when they were moved to the other key, then the additive responses, elicited by the passage of time, may have been directed to the response key by the animal's past experience. The addition of these additive responses would create observed response rates that would be higher during multiple schedules than during simple schedules.

This explanation of the results of Experiment 3 could be tested by replicating Experiment 3 using naive subjects and recording responses to the signal key. If subjects ignored the stimuli on the signal key, as this argument assumes, then no additive responses should occur on the signal key in this experiment. If the animal's past experience is responsible for the higher response rates reported in Experiment 3, then removing this experience by using naive subjects should change the results.

The finding that rate of responding during the VI $x$ component of the multiple schedule was frequently. less than that emitted during the VI $x$ schedule, when the VI x component provided a lower rate of reinforcement than the VI y component, deserves further study. Although the results are suggestive, none of the differences between simple and multiple schedule responding reached statistical significance. Testing this prediction is particularly important because Schwartz (1975) has questioned the part of Rachlin's (1973) theory from which this prediction is drawn.

In closing, the generality of the present results should be tested using different simple schedules, subjects, and responses. Such experiments would test the conflicting predictions of two important theories. They might also broaden the definition of behavioral contrast. Experiments demonstrating positive behavioral contrast frequently show an increase in rate of responding during the $\mathrm{VI} \times$ component when subjects move from a mult VI $x$ VI $x$ schedule to a mult VI $x$ VI $y$ schedule in which the VI $x$ component is more favorable than the VI y component. Experiments demonstrating negative contrast may show a decrease in rate of responding during the VI $\mathrm{x}$ component when subjects move from a mult VI $x$ VI $x$ schedule to a mult VI $x$ VI y schedule in which the VI $x$ component is less favorable than the VI y component. Experiments 2 and 3 found results comparable to positive contrast, and may have found results comparable to negative contrast, if a VI x schedule is substituted for the mult VI $\times$ VI $x$ baseline usually used to assess behavioral contrast. Experiment 1 also supports the substitution of a VI $x$ schedule for the usual mult VI $x$ VI $x$ baseline by showing that rates of responding during the schedules and components are not systematically different. If the present results were replicated, they might expand the current definition of behavioral contrast to include comparisons between simple and multiple schedule responding.

\section{REFERENCES}

Bloomfifi,n, T. M. Behavioral contrast and relative reinforcement frequency in two multiple schedules. Journal of the Experimental Analysis of Behavior, 1967, 10, 151-158.

Bottjer, S. W., Scoble, S. R., \& Wallace, J. Positive behavioral contrast, autoshaping, and omission responding in the goldfish (Carassius auratus). Animal Learning \& Behavior, $1977.5,336-342$

Catania, A. C., \& Reynolids, G. S. A quantitative analysis of the responding maintained by interval schedules of reinforcement. Journal of the Experimental Analysis of Behavior, 1968, 11, 327-383.

DE Villie RS, P. A. Reinforcement and response rate interaction in multiple random-interval avoidance schedules. Journal of the Experimental A nalysis of Behavior, 1972, 18, 499-507.

FREEMAN, B. J. The role of response-independent reinforcement in producing behavioral contrast effects in the rat. Learning and Motivation, 1971, 2, 138-147.

Gamzu, E., \& SchwarT\%, B. The maintenance of key-pecking by stimulus-contingent and response-independent food presentation. Journal of the Experimental Analysis of Behavior, 1973. $19,65.72$

Halliday, M. S., \& Bonkes, R. A. Behavioral contrast without response-rate reduction. Journal of the Experimental Analysis of Behavior, 1974, 22, 453-462.

Hearsi, E., \& Gormi.k, D. Some tests of the additivity (autoshaping) theory of behavioral contrast. Animal Learning \& Behavior, 1976, 4, 145-150

Hearst, E., \& Jenkins, H. M. Sign-tracking: The stimulusreinforcer relation and directed action. Austin. Tex: Psychonomic Society. 1974. 
Hemmes, N. Behavioral contrast in pigeons depends upon the operant. Journal of Comparative and Physiological Psychology, 1973, 85, 171-178.

Herrnstein, R. J. On the law of effect. Journal of the Experimental Analysis of Behavior, 1970, 13, 243-266.

Herrnste in, R. J. Formal properties of the matching law. Journal of the Experimental Analysis of Behavior, 1974, 21, 159-164.

Herrnstein, R. J., \& Loveland, D. H. Hunger and contrast in a multiple schedule. Journal of the Experimental Analysis of Behavior. 1974. 21, 511-517.

JAFFE. M. L. The effects of lesions in the ventromedial nucleus of the hypothalamus on behavioral contrast in rats. Physiological Psychology, 1973, 1, 191-198.

KELLE R, K. The role of elicited responding in behavioral contrast. Journal of the Experimental Analysis of Behavior, 1974, 21, 249-257.

McSwenney, F. K. Negative behavioral contrast on multiple treadle press schedules. Journal of the Experimental Analysis of Behavior, 1978, 29, 463-473.

McSweenfy, F. K., \& Dericco, D. A. Rates of responding in the pigeon generated by simple and complex schedules which provide the same rates of reinforcement. Animal Learning \& Behavior, 1976, 4, 379-385.

Pear, J. J., \& Wilkie, D. M. Contrast and induction in rats on multiple schedules. Journal of the Experimental Analysis of Behavior, 1971, 15, 289-296.

RACHlin, H. C. Contrast and matching. Psychological Review, 1973, 80, 217-234.

Redford, M. E., \& Perkins, C. C., JR. The role of autopecking in behavioral contrast. Journal of the Experimental Analysis of Behavior, 1974, 21, 145-150.

Schwartz, B. Maintenance of key-pecking by response-independent food presentation: The role of the modality of the signal for food. Journal of the Experimental Analysis of Behavior, 1973, 20, 17-22.

Schwartz, B. Behavioral contrast in the pigeon depends upon the location of the stimulus. Bulletin of the Psychonomic Society, 1974, 3, 365-368.

Schwartz, B. Discriminative stimulus location as a determinant of positive and negative behavioral contrast in the pigeon. Journal of the Experimental Analysis of Behavior, 1975, 23, 167-176.

Schwartz, B. Stimulus-reinforcer contingencies and local behavioral contrast. Journal of the Experimental Analysis of Behavior. 1978, 29, 297-308.

Schwartz, B., Hamilton, B., \& Silberberg, A. Behavioral contrast in the pigeon: A study of the duration of key pecking maintained on multiple schedules of reinforcement. Journal of the Experimental Analysis of Behavior, 1975, 24, 199-206.

Spealman, R. D., \& Gollub, L. R. Behavioral interactions in multiple variable interval schedules. Journal of the Experimental Analysis of Behavior, 1974, 22, 471-481.

Staddon, J. E. R. Temporal control, attention and memory. Psychological Review, 1974, 81, 375-391.

WEstв Rook, F. R. Failure to obtain positive contrast when pigeons press a bar. Journal of the Experimental Analysis of Behavior, 1973, 20, 499-510.

White, K. G., \& Braunstein, S. B. Stimulus control of topographically tagged responding. Animal Learning \& Behavior, 1979, 7, 333-338.

Woodruff, G. Behavioral contrast and type of reward: Role of elicited response topography. Animal Learning \& Behavior. $1979,7,339-346$.

(Received for publication November 12, 1979; revision accepted April 8, 1980.)

\section{ERRATUM}

Crawford, L. L., Steele, K. M., \& Malone, J. C., Jr. Gradient form and sequential effects during generalization testing in extinction. Animal Learning \& Behavior, 1980, 8, 245-252-On page 246 , the two sentences at the top of column 2 should correctly read:

[While] the procedure was similar to that of previous studies designed to demonstrate peak shift, such a demonstration was not the main object here. Nonetheless, the elimination of the control group used by Hanson and by others does prevent some comparisons with his data, such as the demonstration of the increased area and the sharpening of the gradient for the discriminative pretraining subjects. 